\title{
Frequency of Cancer Genes on the Chicken Z Chromosome and Its Human Homologues: Implications for Sex Chromosome Evolution
}

\author{
Rami Stiglec, ${ }^{1}$ Matthias Kohn, ${ }^{2}$ James Fong, ${ }^{1}$ Tariq Ezaz, ${ }^{1}$ Horst Hameister, ${ }^{2}$ and \\ Jennifer A. Marshall Graves ${ }^{1}$ \\ ${ }^{1}$ Comparative Genomics Group, Research School of Biological Sciences, The Australian National University, \\ Canberra ACT 0200, Australia \\ ${ }^{2}$ Department of Human Genetics, University of Ulm, 89070 Ulm, Germany
}

Received 31 May 2006; Revised 27 October 2006; Accepted 19 November 2006

Recommended by Peter Little

It has been suggested that there are special evolutionary forces that act on sex chromosomes. Hemizygosity of the $\mathrm{X}$ chromosome in male mammals has led to selection for male-advantage genes, and against genes posing extreme risks of tumor development. A similar bias against cancer genes should also apply to the $\mathrm{Z}$ chromosome that is present as a single copy in female birds. Using comparative database analysis, we found that there was no significant underrepresentation of cancer genes on the chicken Z, nor on the Z-orthologous regions of human chromosomes 5 and 9. This result does not support the hypothesis that genes involved in cancer are selected against on the sex chromosomes.

Copyright (C) 2007 Rami Stiglec et al. This is an open access article distributed under the Creative Commons Attribution License, which permits unrestricted use, distribution, and reproduction in any medium, provided the original work is properly cited.

\section{INTRODUCTION}

In humans, and most other mammals, sex is determined by an XY male: XX female system in which the SRY gene on the Y chromosome determines testis development [1]. The $\mathrm{Y}$ chromosome represents a degraded relic of the $\mathrm{X}$ and has been left with only 45 genes of the 1000 or so it originally had, which are now represented solely on the X [2]. In female placental mammals, $\mathrm{X}$ inactivation randomly silences one $\mathrm{X}$ chromosome, thus maintaining a balanced dosage of $\mathrm{X}$-linked gene products between the sexes.

For an autosomal gene, the missing or inactive products of recessive alleles are complemented by the normal product of the wild-type allele in heterozygotes, producing a wildtype, or intermediate, phenotype. However, hemizygosity for the $\mathrm{X}$ chromosome poses a quandary for males in that deleterious recessive mutations of $\mathrm{X}$-borne genes will have an immediate lethal or harmful effect on phenotype. The absence of a second allele to compensate for the recessive mutant allele means that the frequency of deleterious sex linked recessive conditions (such as colour blindness, haemophilia, and many forms of mental retardation) is far higher in males than females. The same would be true for an X-borne gene in females due to $\mathrm{X}$ inactivation, except that heterozygotes are mosaics for mutant and wild-type tissue, so that phenotype is less severe.

This bias poses a particular problem for genes within which somatic mutation would be lethal, including genes that control somatic growth. It was proposed that genes whose absence cause unregulated growth have been selected against on the human X chromosome, leaving the X depauperate in these "cancer genes" [3].

Genes implicated in cancer can be defined as those that control cell growth, and whose constitutional or somatic mutations cause tumors. There are two classes of such genes: oncogenes, which promote cell growth; and tumor suppressor (TS) genes, which inhibit excess growth. Cancer is initiated after loss-of-function mutations in both alleles of autosomal TS genes. Loss-of-function mutations in such genes may therefore act as dominant cancer susceptibility mutations (e.g., retinoblastoma [4]); since in the presence of a constitutional mutation of one allele, mutation of the wildtype allele in somatic tissue during life produces an early onset of tumor. Gain-of-function mutations of oncogenes also result in cancer because of disruption of the stringent transcriptional control necessary for their cell-autonomous 
activity [5]. XY males would therefore be particularly susceptible to cancer caused by somatic mutations of X-linked cancer genes.

A paucity of potentially cancer-causing genes from the $\mathrm{X}$ chromosome has been suggested to be the result of selection against such genes $[3,6]$. There is a striking absence of potent growth-related and tumor suppressor genes on the human $\mathrm{X}$ chromosome $[3,6]$. Potent oncogenes are also absent from the $\mathrm{X}$ chromosome, and there are few examples of tumorspecific activating mutations on the $\mathrm{X}$, such as translocations and inversions, that could involve oncogene activation [3]. Only a few relatively benign TS genes (such as the prostate cancer susceptibly loci $A R$ and $H P C X$ ) are found on the $\mathrm{X}$ chromosome [7].

More recently, many families of genes expressed in sperm and reexpressed in tumors (testis-cancer antigens) have been discovered on the human X chromosome (listed in the NCBI database), most of which are members of large gene families (e.g., CT45, SSX, SPANX, and MAGE) resulting from gene amplifications [8]. These amplified genes are mammalian or primate specific $[8,9]$ and many of them have important spermatogenesis or sex-specific functions [10]. Cancer genes with paralogues that could complement their function would not pose the same risks as single copy genes on the X. When these amplified genes are discounted, there seems to have been a selection against genes on the $\mathrm{X}$ chromosome with essential cellular functions; mutations in which would cause tumors.

Is the bias against cancer genes a general characteristic of sex chromosomes? This question may be answered by studying birds, in which the female rather than the male is the heterogametic sex. Males have two copies of the large and gene rich $\mathrm{Z}$ chromosome, whereas females have a single copy of the Z, plus the small and heterochromatic W chromosome. Although there appears to be some degree of Z-dosage compensation in birds [11], RNA FISH shows that alleles of both $\mathrm{Z}$ chromosomes are expressed, so that male $\mathrm{ZZ}$ birds are true heterozygotes [12]. We would therefore expect that the hemizygous ZW female bird is as vulnerable to mutations in Zlinked cancer genes as is the XY male mammal. The chicken $\mathrm{Z}$ is therefore predicted to bear disproportionately fewer cancer genes.

According to the generally accepted view, mammalian $\mathrm{X} / \mathrm{Y}$ and avian $\mathrm{Z} / \mathrm{W}$ sex chromosomes evolved independently from two different pairs of ancestral autosomes in a common ancestor with no sex chromosomes [13-15]. Comparative gene mapping between human and chicken (Gallus gallus) supports this hypothesis. Mammalian X chromosome genes localise to autosomes in chicken (mostly GGA 1, 4, and $12[16,17])$, whereas chicken $Z$ genes are largely found in segments of two human (Homo sapiens) autosomes (HSA) 5 and 9, and a smaller segment on 18 [18]. The hypothesis that mammal XX/XY and bird ZZ/ZW systems evolved independently from different autosomal pairs predicts that the chicken and human autosomal regions orthologous to the sex chromosomes ( $\mathrm{X}$ and $\mathrm{Z}$ ) would not have been subject to purifying selection against cancer genes. However, the alternative hypothesis that ancestral mammals shared the ZW system with birds, supported by the extraordinary complex sex chromosome system of the platypus [19], predicts that the Z-orthologous regions of HSA 5 and 9 would still bear a bias against cancer genes.

It should therefore be possible to locate and characterise cancer genes on sex chromosomes and their autosomal orthologues, and determine if any were lost from the sex chromosomes of one lineage or the other. Here we test the hypothesis that, like the mammal $\mathrm{X}$, the bird $\mathrm{Z}$ underwent sexchromosome-specific cleansing of cancer genes to protect the heterogametic sex from tumor-causing mutations, and predict that the chicken $\mathrm{Z}$ chromosome is depleted of cancer genes, as is the human $\mathrm{X}$.

Since we have little direct knowledge of avian cancer genes, most information is available for the chicken $\mathrm{Z}$ via its human orthologues. We therefore searched for oncogenes and TS genes on the regions on human chromosomes 5 and 9 orthologous to the chicken $\mathrm{Z}$ chromosome, and then searched for chicken orthologous of these genes. We used the non-Z-homologous regions of the same human chromosomes as controls. We demonstrated that the frequency of cancer genes is the same on the chicken $\mathrm{Z}$ and autosomes, suggesting that the chicken $\mathrm{Z}$ chromosome has not undergone a purification of cancer genes to protect hemizygotic females. Nor did we find significant difference between the frequency of cancer genes versus noncancer genes in the Zhomologous and chicken autosomal-homologous regions of human chromosomes 5 and 9, consistent with the hypothesis that the mammal XY and bird ZW sex chromosome systems evolved independently.

\section{METHODS}

Using the web-based NCBI and UCSC human and chicken databases we looked at 1,876 HSA 5 and 9 protein coding genes (981 and 895, resp.) and constructed a detailed chicken-human comparative map of these chromosomes. The location of chicken orthologues of human genes in the chicken genome was determined via the UCSC Chicken Genome Browser Gateway on the latest assembly of the chicken genome (May 2006, galGal3).

An index of human cancer genes, with corresponding chromosomal locations, was compiled from the NCBI database (key search words were "human cancer," "human tumor suppressor," and "human oncogene"). This index was used to extract a list of 175 cancer genes on HSA 5 (Table 1) and HSA 9 (Table 2), within and outside the regions of orthology with the chicken Z. Each of these cancer genes was then used to screen the chicken databases and the positions of these orthologues on chicken chromosome were established (Table 3).

\section{RESULTS}

There have been no comprehensive comparative analyses of the locations of cancer genes in the chicken genome. Our strategy was therefore to use a comparative bioinformatics approach to identify the regions of HSA 5 and 9 homologous 
TABLE 1: List of 89 cancer genes from human chromosome 5 and their locations in the chicken genome.

\begin{tabular}{|c|c|c|c|c|}
\hline $\begin{array}{l}\text { Gene } \\
\text { Symbol }^{1}\end{array}$ & $\begin{array}{l}\text { Accession } \\
\text { number }\end{array}$ & $\begin{array}{l}\text { Type of } \\
\text { cancer gene }\end{array}$ & $\begin{array}{l}\text { Chromosome } \\
\text { location in human }\end{array}$ & $\begin{array}{l}\text { Chromosome } \\
\text { location in chicken }\end{array}$ \\
\hline$\overline{A H R R}$ & NM_020731 & - & $5 p 15.3$ & 2 \\
\hline TERT & NM_198253 & Oncogene & $5 p 15.33$ & 2 \\
\hline SRD5A1 & NM_001047 & - & $5 \mathrm{p} 15$ & 2 \\
\hline AMACR & NM_014324 & - & $5 p 13.2-q 11.1$ & $\mathrm{Z}$ \\
\hline PRLR & NM_000949 & - & $5 p 14-p 13$ & $\mathrm{Z}$ \\
\hline SKP2 & NM_005983 & $\mathrm{TS}^{2}$ & $5 p 13$ & $\mathrm{Z}$ \\
\hline GDNF & NM_000514 & - & $5 \mathrm{p} 13.1-\mathrm{p} 12$ & $\mathrm{Z}$ \\
\hline DAB2 & NM_001343 & TS & $5 \mathrm{p} 13$ & $\mathrm{Z}$ \\
\hline GHR & NM_000163 & - & $5 p 13-p 12$ & $\mathrm{Z}$ \\
\hline ITGA1 & NM_181501 & - & $5 q 11.2$ & $\mathrm{Z}$ \\
\hline ITGA2 & NM_002203 & - & $5 q 23-q 31$ & $\mathrm{Z}$ \\
\hline GZMA & NM_006144 & TS & $5 q 11-q 12$ & $\mathrm{Z}$ \\
\hline PPAP2A & NM_176895 & - & $5 q 11$ & $\mathrm{Z}$ \\
\hline RAB3C & NM_138453 & Oncogene & $5 q 13$ & $\mathrm{Z}$ \\
\hline MAP3K1 & XM_424734 & - & $5 q 11.2$ & $\mathrm{Z}$ \\
\hline SDCCAG10 & NM_005869 & - & $5 q 12.3$ & $\mathrm{Z}$ \\
\hline PIK3R1 & NM_181523 & - & $5 q 13.1$ & $\mathrm{Z}$ \\
\hline CCNB1 & NM_031966 & - & $5 q 12$ & 10 \\
\hline RAD17 & NM_133338 & - & $5 q 13$ & $\mathrm{Z}$ \\
\hline OCLN & NM_002538 & - & $5 q 13.1$ & $\mathrm{Z}$ \\
\hline ENC1 & NM_003633 & TS & $5 q 12-q 13.3$ & $\mathrm{Z}$ \\
\hline $\mathrm{F} 2 \mathrm{R}$ & NM_001992 & - & $5 q 13$ & $\mathrm{Z}$ \\
\hline F2RL1 & NM_005242 & - & $5 q 13$ & $\mathrm{Z}$ \\
\hline MSH3 & NM_002439 & - & $5 q 11-q 12$ & $\mathrm{Z}$ \\
\hline SSBP2 & NM_012446 & TS & $5 \mathrm{q} 14.1$ & $\mathrm{Z}$ \\
\hline XRCC4 & NM_022406 & - & $5 q 13-q 14$ & $\mathrm{Z}$ \\
\hline CSPG2 & NM_004385 & - & $5 q 14.3$ & $\mathrm{Z}$ \\
\hline GLRX & NM_205160 & - & $5 q 14$ & $\mathrm{Z}$ \\
\hline ELL2 & NM_012081 & TS & $5 q 15$ & $\mathrm{Z}$ \\
\hline PCSK1 & NM_000439 & - & $5 q 15-q 21$ & $\mathrm{Z}$ \\
\hline FER & NM_005246 & - & $5 q 21$ & $\mathrm{Z}$ \\
\hline CAMK4 & NM_001744 & - & $5 q 21.3$ & $\mathrm{Z}$ \\
\hline APC & NM_000038 & TS & $5 q 21-q 22$ & $\mathrm{Z}$ \\
\hline MCC & NM_002387 & TS & $5 q 21-q 22$ & $\mathrm{Z}$ \\
\hline TRIM36 & NM_018700 & TS & $5 q 22.3$ & $\mathrm{Z}$ \\
\hline PGGT1B & NM_005023 & - & $5 q 22.3$ & $\mathrm{Z}$ \\
\hline CCDC112 & NM_001040440 & - & $5 q 22.3$ & $\mathrm{Z}$ \\
\hline TNFAIP8 & NM_014350 & - & $5 \mathrm{q} 23.1$ & $\mathrm{Z}$ \\
\hline LOX & NM_002317 & TS & $5 q 23.2$ & $\mathrm{Z}$ \\
\hline HINT1 & NM_005340 & TS & $5 q 31.2$ & $\mathrm{Z}$ \\
\hline GMCSF & NM_001007078 & - & $5 q 31.1$ & 13 \\
\hline IRF1 & NM_002198 & TS & $5 q 31.1$ & 13 \\
\hline IL4 & NM_001007079 & - & $5 q 31.1$ & 13 \\
\hline AFF4 & NM_014423 & - & $5 q 31$ & 13 \\
\hline HSPA4 & NM_002154 & - & $5 q 31.1-q 31.2$ & 13 \\
\hline TCF7 & NM_003202 & TS & $5 q 31.1$ & 13 \\
\hline TGFBI & NM_000358 & TS & $5 q 31$ & 13 \\
\hline KIF20A & NM_005733 & TS & $5 q 31$ & 13 \\
\hline $\mathrm{CDC} 23$ & NM_004661 & TS & $5 q 31$ & 13 \\
\hline
\end{tabular}


TABle 1: Continued.

\begin{tabular}{|c|c|c|c|c|}
\hline $\begin{array}{l}\text { Gene } \\
\text { Symbol }^{1}\end{array}$ & $\begin{array}{l}\text { Accession } \\
\text { number }\end{array}$ & $\begin{array}{l}\text { Type of } \\
\text { cancer gene }\end{array}$ & $\begin{array}{l}\text { Chromosome } \\
\text { location in human }\end{array}$ & $\begin{array}{l}\text { Chromosome } \\
\text { location in chicken }\end{array}$ \\
\hline JMJD1B & NM_016604 & TS & $5 q 31$ & 13 \\
\hline EGR1 & NM_001964 & TS & $5 q 31.1$ & 13 \\
\hline HSPA9B & NM_004134 & TS & $5 q 31.1$ & 13 \\
\hline CTNNA1 & NM_001903 & - & $5 q 31$ & 13 \\
\hline PURA & NM_005859 & TS & $5 q 31$ & 13 \\
\hline SRA1 & NM_001035235 & - & $5 q 31.3$ & 13 \\
\hline HDAC3 & NM_003883 & TS & $5 q 31$ & 13 \\
\hline RNF14 & NM_004290 & - & $5 q 23.3-q 31.1$ & 13 \\
\hline FGF1 & NM_000800 & - & $5 q 31$ & 13 \\
\hline NR3C1 & NM_001018077 & TS & $5 q 31.3$ & 13 \\
\hline PPP2R2B & NM_004576 & TS & $5 q 31-5 q 32$ & 13 \\
\hline SPINK1 & NM_003122 & - & $5 q 32$ & 4 \\
\hline SPINK5 & NM_006846 & - & $5 q 32$ & 13 \\
\hline SPINK5L2 & NM_001001325 & - & 5 & - \\
\hline SPINK5L3 & NM_001040129 & - & $5 q 32$ & - \\
\hline ECG2 & NM_032566 & - & $5 q 32$ & - \\
\hline CSNK1A1 & NM_001025105 & - & $5 q 32$ & 13 \\
\hline CSF1R & NM_005211 & Oncogene & $5 q 33-q 35$ & 13 \\
\hline PDGFRB & NM_002609 & - & $5 q 31-q 32$ & 13 \\
\hline CDX1 & NM_001804 & - & $5 q 31-q 33$ & 13 \\
\hline FAT2 & NM_001447 & TS & $5 q 32-q 33$ & 13 \\
\hline SPARC & NM_003118 & - & $5 q 31.3-q 32$ & 13 \\
\hline ATOX1 & NM_004045 & - & $5 q 32$ & 13 \\
\hline IL12B & NM_002187 & - & $5 q 31.1-q 33.1$ & 13 \\
\hline PTTG1 & NM_004219 & - & $5 q 35.1$ & 13 \\
\hline CCNG1 & NM_004060 & TS & $5 q 32-q 34$ & 13 \\
\hline HMMR & NM_012484 & - & 5q33.2-qter & 13 \\
\hline TLX3 & NM_021025 & Oncogene & $5 q 35.1$ & 13 \\
\hline NPM1 & NM_002520 & TS & $5 q 35$ & 13 \\
\hline FGF18 & NM_003862 & Oncogene & $5 q 34$ & 13 \\
\hline DUSP1 & NM_004417 & - & $5 q 34$ & 13 \\
\hline UNC5A & NM_133369 & TS & $5 q 35.2$ & 13 \\
\hline FGFR4 & XM_414474 & - & 5q35.1-qter & 13 \\
\hline RAB24 & NM_001031677 & Oncogene & $5 q 35.3$ & 13 \\
\hline NOLA2 & NM_017838 & - & $5 q 35.3$ & 13 \\
\hline SQSTM1 & NM_003900 & - & $5 q 35$ & 13 \\
\hline MAPK9 & NM_002752 & TS & $5 q 35$ & 13 \\
\hline FLT4 & NM_182925 & - & $5 q 34-q 35$ & 13 \\
\hline SCGB3A1 & NM_052863 & TS & 5q35-qter & 13 \\
\hline GNB2L1 & NM_006098 & Oncogene & $5 q 35.3$ & 16 \\
\hline
\end{tabular}

${ }^{1}$ Human gene symbol.

${ }^{2} \mathrm{TS}$ : tumor suppressor gene.

to the chicken $\mathrm{Z}$, and outside the regions of homology, to identify cancer genes within these human chromosome regions, then to ascertain how many of these were retained on the chicken $\mathrm{Z}$ versus chicken autosomes.

There was a total of 175 cancer genes on HSA 5 and 9. Of these, 82 lay within the Z-homologous regions, and 93 lay outside these regions. The highest concentration of cancer genes in both HSA 5 and 9 was located on the terminal regions of their long arms.

Of the 175 human cancer genes, 164 had clear orthologues in the chicken genome; seven were absent from the chicken genome. Of the seven apparently missing from the chicken genome, two (SPINK4 and CCL21) lay in Z-homologous regions of HSA 5 and HSA 9, and nine 
TABLE 2: List of 86 cancer genes from human chromosome 9 and their locations in the chicken genome.

\begin{tabular}{|c|c|c|c|c|}
\hline $\begin{array}{l}\text { Gene } \\
\text { Symbol }^{1}\end{array}$ & $\begin{array}{l}\text { Accession } \\
\text { number }\end{array}$ & $\begin{array}{l}\text { Type of } \\
\text { cancer gene }\end{array}$ & $\begin{array}{l}\text { Chromosome } \\
\text { location in human }\end{array}$ & $\begin{array}{l}\text { Chromosome } \\
\text { location in chicken }\end{array}$ \\
\hline SMARCA2 & NM_003070 & $\mathrm{TS}^{2}$ & $9 \mathrm{p} 22.3$ & $\mathrm{Z}$ \\
\hline ANKRD15 & NM_015158 & TS & 9 p24 & Z \\
\hline JAK2 & NM_004972 & - & 9 p24 & $\mathrm{Z}$ \\
\hline $\mathrm{CD} 274$ & NM_014143 & - & 9 p24 & $\mathrm{Z}$ \\
\hline PDCD1LG2 & NM_025239 & - & $9 \mathrm{p} 24.2$ & Z \\
\hline MLLT3 & NM_004529 & - & 9 p22 & $\mathrm{Z}$ \\
\hline IFNB1 & NM_002176 & TS & 9 p21 & Unknown ${ }^{3}$ \\
\hline IFNA17 & NM_021268 & - & 9 p22 & Unknown \\
\hline MTAP & NM_002451 & TS & 9 p21 & $\mathrm{Z}$ \\
\hline CDKN2A & NM_204433 & TS & $9 \mathrm{p} 21$ & $\mathrm{Z}$ \\
\hline CDKN2B & NM_004936 & TS & $9 \mathrm{p} 21$ & 8 \\
\hline TUSC1 & NM_001004125 & TS & $9 \mathrm{p} 21.2$ & $\mathrm{Z}$ \\
\hline TOPORS & NM_005802 & TS & $9 \mathrm{p} 21$ & $\mathrm{Z}$ \\
\hline B4GALT1 & NM_001497 & - & $9 \mathrm{p} 13$ & $\mathrm{Z}$ \\
\hline SPINK4 & NM_014471 & - & $9 \mathrm{p} 13.3$ & - \\
\hline BAG1 & NM_004323 & - & $9 \mathrm{p} 12$ & 2 \\
\hline UBAP1 & NM_016525 & TS & $9 p 22-p 21$ & $\mathrm{Z}$ \\
\hline NUDT2 & NM_001161 & TS & $9 \mathrm{p} 13$ & $\mathrm{Z}$ \\
\hline GALT & NM_000155 & - & $9 \mathrm{p} 13$ & $\mathrm{Z}$ \\
\hline IL11RA & NM_004512 & - & $9 \mathrm{p} 13$ & $\mathrm{Z}$ \\
\hline CCL21 & NM_002989 & - & $9 \mathrm{p} 13$ & - \\
\hline FANCG & NM_204378 & - & $9 \mathrm{p} 13$ & $\mathrm{Z}$ \\
\hline CA9 & NM_001216 & TS & $9 p 13-p 12$ & $\mathrm{Z}$ \\
\hline TLN1 & NM_006289 & TS & $9 \mathrm{p} 13$ & Z \\
\hline RECK & NM_021111 & - & $9 \mathrm{p} 13-\mathrm{p} 12$ & 2 \\
\hline PAX5 & NM_016734 & Oncogene & $9 \mathrm{p} 13$ & $\mathrm{Z}$ \\
\hline IGFBPL1 & NM_001007563 & TS & $9 \mathrm{p} 13.1$ & 4 \\
\hline ALDHA1 & NM_000689 & - & $9 q 21.13$ & $\mathrm{Z}$ \\
\hline ANXA1 & NM_000700 & TS & $9 \mathrm{q} 12-\mathrm{q} 21.2$ & $\mathrm{Z}$ \\
\hline GCNT1 & NM_001490 & - & $9 q 13$ & $\mathrm{Z}$ \\
\hline UBQLN1 & NM_013438 & Oncogene & $9 q 21.2-q 21.3$ & $\mathrm{Z}$ \\
\hline NTRK2 & NM_006180 & Oncogene & $9 \mathrm{q} 22.1$ & $\mathrm{Z}$ \\
\hline GAS1 & NM_002048 & TS & $9 \mathrm{q} 21.3-\mathrm{q} 22$ & $\mathrm{Z}$ \\
\hline DAPK1 & NM_004938 & Oncogene & $9 \mathrm{q} 34.1$ & $\mathrm{Z}$ \\
\hline CTSL & NM_001912 & - & $9 q 21-q 22$ & $\mathrm{Z}$ \\
\hline SHC3 & NM_016848 & - & $9 q 22.1-q 22.2$ & $\mathrm{Z}$ \\
\hline GADD45G & NM_006705 & TS & $9 q 22.1-q 22.2$ & Unknown \\
\hline SYK & NM_003177 & TS & $9 q 22$ & $\mathrm{Z}$ \\
\hline WNK2 & NM_006648 & - & $9 q 22.3$ & 12 \\
\hline FANCC & NM_000136 & TS & $9 q 22.3$ & $\mathrm{Z}$ \\
\hline PTCH1 & NM_000264 & TS & $9 q 22.3$ & $\mathrm{Z}$ \\
\hline CDC14B & NM_033331 & TS & $9 q 22.33$ & $\mathrm{Z}$ \\
\hline XPA & NM_204853 & - & $9 q 22.3$ & $\mathrm{Z}$ \\
\hline ANP32B & NM_006401 & TS & $9 q 22.32$ & 28 \\
\hline GALNT12 & NM_024642 & - & $9 q 22.33$ & 2 \\
\hline TGFBR1 & NM_004612 & - & $9 q 22$ & 2 \\
\hline NR4A3 & NM_006981 & - & $9 q 22$ & 2 \\
\hline TMEFF1 & NM_003692 & TS & $9 q 31$ & 2 \\
\hline KLF4 & NM_004235 & TS & $9 q 31$ & Unknown \\
\hline TXN & NM_003329 & - & $9 q 31$ & $\mathrm{Z}$ \\
\hline
\end{tabular}


TABle 2: Continued.

\begin{tabular}{|c|c|c|c|c|}
\hline $\begin{array}{l}\text { Gene } \\
\text { Symbol }^{1}\end{array}$ & $\begin{array}{l}\text { Accession } \\
\text { number }\end{array}$ & $\begin{array}{l}\text { Type of } \\
\text { cancer gene }\end{array}$ & $\begin{array}{l}\text { Chromosome } \\
\text { location in human }\end{array}$ & $\begin{array}{l}\text { Chromosome } \\
\text { location in chicken }\end{array}$ \\
\hline EDG2 & NM_001401 & - & $9 q 31.3$ & Z \\
\hline UGCG & NM_003358 & - & $9 q 31$ & $\mathrm{Z}$ \\
\hline AMBP & NM_001633 & - & $9 q 32-q 33$ & 17 \\
\hline TNFSF15 & NM_005118 & - & $9 q 32$ & 17 \\
\hline TNC & NM_002160 & - & $9 q 33$ & 17 \\
\hline DEC1 & NM_017418 & TS & $9 q 32$ & - \\
\hline TRIM32 & NM_012210 & Oncogene & $9 q 31-q 34.1$ & 17 \\
\hline TLR4 & NM_138554 & - & $9 q 32-q 33$ & 17 \\
\hline $\mathrm{DBC} 1$ & NM_014618 & TS & $9 q 32-q 33$ & 17 \\
\hline TRAF1 & NM_005658 & - & $9 q 33-q 34$ & 17 \\
\hline RAB14 & NM_016322 & Oncogene & $9 q 32-q 34.11$ & 17 \\
\hline GSN & NM_000177 & - & $9 q 33$ & 17 \\
\hline DAB2IP & NM_032552 & TS & $9 q 33.1-q 33.3$ & 17 \\
\hline PTGS1 & NM_000962 & - & $9 q 32-q 33.3$ & 17 \\
\hline NR5A1 & NM_004959 & TS & $9 q 33$ & 17 \\
\hline FPGS & NM_004957 & - & $9 \mathrm{q} 34.1$ & 17 \\
\hline ENG & NM_000118 & - & $9 q 33-q 34.1$ & 17 \\
\hline LCN2 & NM_005564 & Oncogene & $9 q 34$ & - \\
\hline SET & NM_003011 & TS & $9 q 34$ & 17 \\
\hline PKN3 & NM_013355 & TS & $9 q 34.11$ & 17 \\
\hline PTGES & NM_004878 & TS & $9 \mathrm{q} 34.3$ & 17 \\
\hline ABL1 & NM_005157 & Oncogene & $9 \mathrm{q} 34.1$ & 17 \\
\hline NUP214 & NM_005085 & Oncogene & $9 \mathrm{q} 34.1$ & 17 \\
\hline RAPGEF1 & NM_198679 & Oncogene & $9 q 34.3$ & 17 \\
\hline TSC1 & NM_000368 & TS & $9 q 34$ & 17 \\
\hline RALGDS & NM_001042368 & TS & $9 q 34.3$ & 17 \\
\hline RPL7A & NM_001004379 & Oncogene & $9 q 34$ & 17 \\
\hline SURF1 & NM_003172 & Oncogene & $9 q 34$ & 17 \\
\hline ADAMTS13 & NM_139025 & - & $9 q 34$ & 17 \\
\hline VAV2 & NM_003371 & Oncogene & $9 \mathrm{q} 34.1$ & 17 \\
\hline RXRA & NM_002957 & - & $9 \mathrm{q} 34.3$ & 17 \\
\hline SDCCAG3 & NM_001039707 & - & $9 q 34.3$ & 17 \\
\hline NOTCH1 & NM_017617 & TS & $9 \mathrm{q} 34.3$ & 17 \\
\hline AGPAT2 & NM_006412 & - & $9 q 34.3$ & 17 \\
\hline COBRA1 & NM_015456 & - & $9 \mathrm{p} 34$ & 17 \\
\hline NOXA1 & NM_006647 & - & $9 q 34.3$ & 17 \\
\hline
\end{tabular}

${ }^{1}$ Human gene symbol.

${ }^{2}$ TS: tumor suppressor gene.

${ }^{3}$ Unknown: the nucleotide sequence of the gene is annotated in the chicken genome assembly but its chromosomal location is not yet known.

lay in non-Z-homologous regions of these chromosome. tBLASTx searches for SPINK4 and CCL21 return moderate-level hits on the chicken genome (accession numbers BX934389 and CR522995, resp.) both of which are Z-link sequences.

This suggests that although these genes might be Z-linked in chickens, their sequences have drastically diverged at the nucleotide level; as such, they have not been included in our analysis. Of the 164 chicken orthologues, 72 localised to the chicken $\mathrm{Z}$ chromosome (Table 3 ). There were only four genes in the Z-homologous region that mapped to chicken autosomes.

Of the remainder of the human cancer genes with detectable orthologues in the chicken genome, 92 localised to chicken autosomes and four had not yet been localised to a specific chromosome (although all four were found in Z-homologous regions and could be $\mathrm{Z}$ genes; the uncertainty of their location, however, meant that they were not included in our analysis) (Table 3). Nearly all the nonZ-homologous HSA 5 genes mapped to GGA 13 and most 
TABLE 3: Summary of the localisations of cancer genes from human chromosomes 5 and 9 in the chicken genome.

\begin{tabular}{lcrr}
\hline $\begin{array}{l}\text { Chicken } \\
\text { chromosomes } \\
\text { (GGA) }\end{array}$ & \multicolumn{2}{l}{$\begin{array}{l}\text { Human } \\
\text { chromosomes } \\
\text { (HSA) }\end{array}$} & Total \\
\hline Z & 5 & 9 & 72 \\
2 & 36 & 36 & 9 \\
4 & 3 & 6 & 2 \\
8 & 1 & 1 & 1 \\
10 & - & 1 & 1 \\
12 & 1 & - & 1 \\
13 & - & 1 & 44 \\
16 & 44 & - & 1 \\
17 & 1 & - & 32 \\
28 & - & 32 & 1 \\
\hline Autosomal total & - & 1 & 92 \\
\hline Unknown chromosome & 0 & 42 & 4 \\
Mammal-specific & 3 & 4 & 7 \\
\hline Combined total & 89 & 4 & 175 \\
\hline
\end{tabular}

non-Z-homologous HSA 9 genes to GGA 17, with six on GGA 2 and a few singletons (possibly mis-mapped or misidentified). GGA 13, which shows partial colinearity with HSA 5, has 44 cancer genes; and GGA 17, which, with the exception of a few inversions, demonstrates colinearity with HSA 9, has 32 cancer genes.

We then compared the frequencies of human cancer genes among total genes in the Z-homologous regions of HSA 5 and $9(9.3 \%)$ and the autosome-homologous regions of HSA 5 and $9(10.0 \%)$, which are not significantly different by a chi-squared test on frequencies (Table 4). Then we compared the frequencies of cancer genes on the chicken $\mathrm{Z}$ $(13.7 \%)$ with the frequencies of the autosomal regions on the rest of HSA 5 and HSA 9 (13.9\%), which is also nonsignificant.

\section{DISCUSSION}

An underrepresentation of tumour suppressor genes and oncogenes on the human X chromosome $[3,6]$ has been explained by the hypothesis that such genes are selected against because of their propensity for somatic mutation to cause cancer. Hameister and Adolph's [3] original claim that the human X chromosome is depleted of cancer genes has been challenged by new analyses of human genome data, which show that the human X contains many primate-specific families of cancer genes such as the synovial sarcoma X (SSX) breakpoint family; the cancer/testis antigen families: CT45, CTAG, SPANX, plus the GAGE cancer/testis antigen subfamilies: XAGE, PAGE, and MAGE, which appear to be amplified within large palindromes. These cancer/testis antigen genes play an essential role in normal testis development and function and may be just upregulated in tumour tissues rather than involved in tumourigenesis. If these duplicated genes are discounted, the human $\mathrm{X}$ does indeed appear to be depleted in cancer genes.

This hypothesis implies that once an $\mathrm{X}$ chromosomal region stopped undergoing recombination with the proto$\mathrm{Y}$ chromosome, there was strong selection for loss of cancer genes on the $\mathrm{X}$ (deleted or translocated to an autosome), or loss of their cancer-causing function. Only physical loss could be detected by our comparative bioinformatics strategy.

Our study provides no evidence that selection against cancer genes has occurred on the chicken $\mathrm{Z}$ chromosome. We observed that the frequency of cancer gene orthologues on the chicken $\mathrm{Z}$ is not significantly different from the frequency of cancer gene orthologues on the chicken autosome regions that share HSA 5 and HSA 9 with the $Z$. Nor is the frequency of cancer genes within the Z-homologous and Znonhomologous regions of HSA 5 and 9 different.

This result does not support the hypothesis that cancer genes on the $\mathrm{Z}$ are selected against because of their hemizygotic presence in female chickens. Thus paucity of cancer genes is not a universal characteristic of sex chromosomes.

A major source of uncertainly in this study is the definition of "cancer genes" in humans and chickens, and whether the chicken orthologues of human cancer genes are also involved in cancer. Many of the human cancer genes on HSA 5 and 9 are involved in breast cancer, so may have a cancer-causing potential only in mammals. The exact role of many human (let alone chicken) growth-regulating genes in disease is unknown. Although some genes in the human cancer gene database we used were identified as oncogenes or tumour suppressors (Tables 1 and 2), it is uncertain whether these genes actually initiate tumour development or they are merely upregulated in cancer tissues by other upstream genes. Many genes (particularly the amplified primate-specific genes) were labeled as testis-cancer antigens on the basis of their re-expression in some cancers. Because there are few direct data concerning avian cancer genes, we had to make the working assumption that chicken homologues of human cancer genes are also involved in avian cancer. Although we cannot be certain that human cancer genes are involved with cancer in chickens, all human oncogenes and TS genes have essential cell-cycle functions, so conserved orthologues are expected to possess similar roles.

There is an apparent loss of cancer genes from the human $X$, but not the chicken $Z$, which suggests that the cancer gene contents of the $\mathrm{X}$ and $\mathrm{Z}$ are under different selection pressures. This could be a function of the different life spans between chickens and humans. Hunter and Cozma [20] demonstrated that cancer latency and life span are linkedcancer acts as a somatic recessive in long-lived species such as humans, but a dominant in short-lived species such as mice, which reproduce before they succumb to a tumour.

We observed, also, that the regions of human chromosomes 5 and 9 that are orthologous to chicken $\mathrm{Z}$ were not significantly depleted of cancer genes, implying that these regions do not bear the legacy of once having been sex chromosomes, as suggested by Grützner et al. [19]. 
TABLE 4: Frequencies of cancer genes versus total genes in regions of human chromosomes 5 and 9 that are homologous to the chicken $\mathrm{Z}$ chromosome and to chicken autosomes. Human genes refer to all genes within these regions regardless of their homology, or lack thereof, to chicken genes. Chicken genes refer only to genes within these regions that have homolouges in the chicken genome. Chi-square analysis of these frequencies demonstrates that the differences between these regions are not significant.

\begin{tabular}{l|ccc}
\hline Genes & $\begin{array}{l}\text { Z-homologous } \\
\text { regions }\end{array}$ & $\begin{array}{l}\text { Non-Z homologous } \\
\text { regions }\end{array}$ & $\begin{array}{l}\text { Chi-square value } \\
(1 \text { degree of freedom })\end{array}$ \\
\hline Human genes & $78 / 841(9.28 \%)$ & $91 / 908(10.02 \%)$ & $0.23020, p \leq 1$ \\
Chicken genes & $72 / 526(13.69 \%)$ & $86 / 621(13.85 \%)$ & $0.00468, p \leq 1$ \\
\hline
\end{tabular}

Our analysis reveals that cancer genes occur at the same frequency on the chicken $\mathrm{Z}$ chromosome as on chicken autosomes. Thus, we have established that hemizygotic selection pressures on cancer genes are not a universal characteristic of heterogametic sex chromosomes. This challenges the assumption that both XX/XY and ZZ/ZW systems are subject to similar sex-chromosome-specific evolutionary selection pressures, and urges caution in interpretation of observations on biased gene content of sex chromosomes.

\section{REFERENCES}

[1] A. H. Sinclair, P. Berta, M. S. Palmer, et al., "A gene from the human sex-determining region encodes a protein with homology to a conserved DNA-binding motif," Nature, vol. 346, no. 6281 , pp. 240-244, 1990.

[2] J. A. Marshall Graves, "Sex chromosome specialization and degeneration in mammals," Cell, vol. 124, no. 5, pp. 901-914, 2006.

[3] H. Hameister and S. Adolph, "Oncogenes and the mammalian X chromosome," Human Genetics, vol. 72, no. 3, pp. 241-244, 1986.

[4] K. W. Choy, C. P. Pang, C. B. Yu, et al., "Loss of heterozygosity and mutations are the major mechanisms of RB1 gene inactivation in Chinese with sporadic retinoblastoma," Human Mutation, vol. 20, no. 5, p. 408, 2002.

[5] T. Sandal, "Molecular aspects of the mammalian cell cycle and cancer," Oncologist, vol. 7, no. 1, pp. 73-81, 2002.

[6] J. A. Marshall Graves, J. Gécz, and H. Hameister, "Evolution of the human $\mathrm{X}$ - a smart and sexy chromosome that controls speciation and development," Cytogenetic and Genome Research, vol. 99, no. 1-4, pp. 141-145, 2002.

[7] J. Xu, D. Meyers, D. Freije, et al., "Evidence for a prostate cancer susceptibility locus on the X chromosome," Nature Genetics, vol. 20, no. 2, pp. 175-179, 1998.

[8] E. Betrán, J. J. Emerson, H. Kaessmann, and M. Long, "Sex chromosomes and male functions: where do new genes go?" Cell Cycle, vol. 3, no. 7, pp. 873-875, 2004.

[9] J. J. Emerson, H. Kaessmann, E. Betrán, and M. Long, "Extensive gene traffic on the mammalian X chromosome," Science, vol. 303, no. 5657, pp. 537-540, 2004.

[10] M. Delbridge and J. A. Marshall Graves, "Origin and evolution of spermatogenesis genes on the human sex chromosomes," in SRF Supplement - Spermatology, Nottingham University Press, (in press).

[11] H. A. McQueen, D. McBride, G. Miele, A. P. Bird, and M. Clinton, "Dosage compensation in birds," Current Biology, vol. 11, no. 4, pp. 253-257, 2001.

[12] J. A. Marshall Graves, "Sex and death in birds: a model of dosage compensation that predicts lethality of sex chromo- some aneuploids," Cytogenetic and Genome Research, vol. 101, no. 3-4, pp. 278-282, 2003.

[13] A.-K. Fridolfsson, H. Cheng, N. G. Copeland, et al., "Evolution of the avian sex chromosomes from an ancestral pair of autosomes," Proceedings of the National Academy of Sciences of the United States of America, vol. 95, no. 14, pp. 8147-8152, 1998.

[14] S. Shetty, D. K. Griffin, and J. A. Marshall Graves, "Comparative painting reveals strong chromosome homology over 80 million years of bird evolution," Chromosome Research, vol. 7, no. 4, pp. 289-295, 1999.

[15] I. Nanda, C. Sick, U. Münster, et al., "Sex chromosome linkage of chicken and duck type I interferon genes: further evidence of evolutionary conservation of the Z chromosome in birds," Chromosoma, vol. 107, no. 3, pp. 204-210, 1998.

[16] M. Schmid, I. Nanda, M. Guttenbach, et al., "First report on chicken genes and chromosomes 2000," Cytogenetics and Cell Genetics, vol. 90, no. 3-4, pp. 169-218, 2000.

[17] M. Kohn, H. Kehrer-Sawatzki, W. Vogel, J. A. Marshall Graves, and H. Hameister, "Wide genome comparisons reveal the origins of the human X chromosome," Trends in Genetics, vol. 20, no. 12, pp. 598-603, 2004.

[18] I. Nanda, E. Zend-Ajusch, Z. Shan, et al., "Conserved synteny between the chicken $\mathrm{Z}$ sex chromosome and human chromosome 9 includes the male regulatory gene DMRT1: a comparative (re)view on avian sex determination," Cytogenetics and Cell Genetics, vol. 89, no. 1-2, pp. 67-78, 2000.

[19] F. Grützner, W. Rens, E. Tsend-Ayush, et al., "In the platypus a meiotic chain of ten sex chromosomes shares genes with the bird Z and mammal X chromosomes," Nature, vol. 432, no. 7019, pp. 913-917, 2004.

[20] K. Hunter and D. Cozma, "The mouse in cancer research past, present, future," Current Genomics, vol. 2, no. 1, pp. 1-26, 2001. 

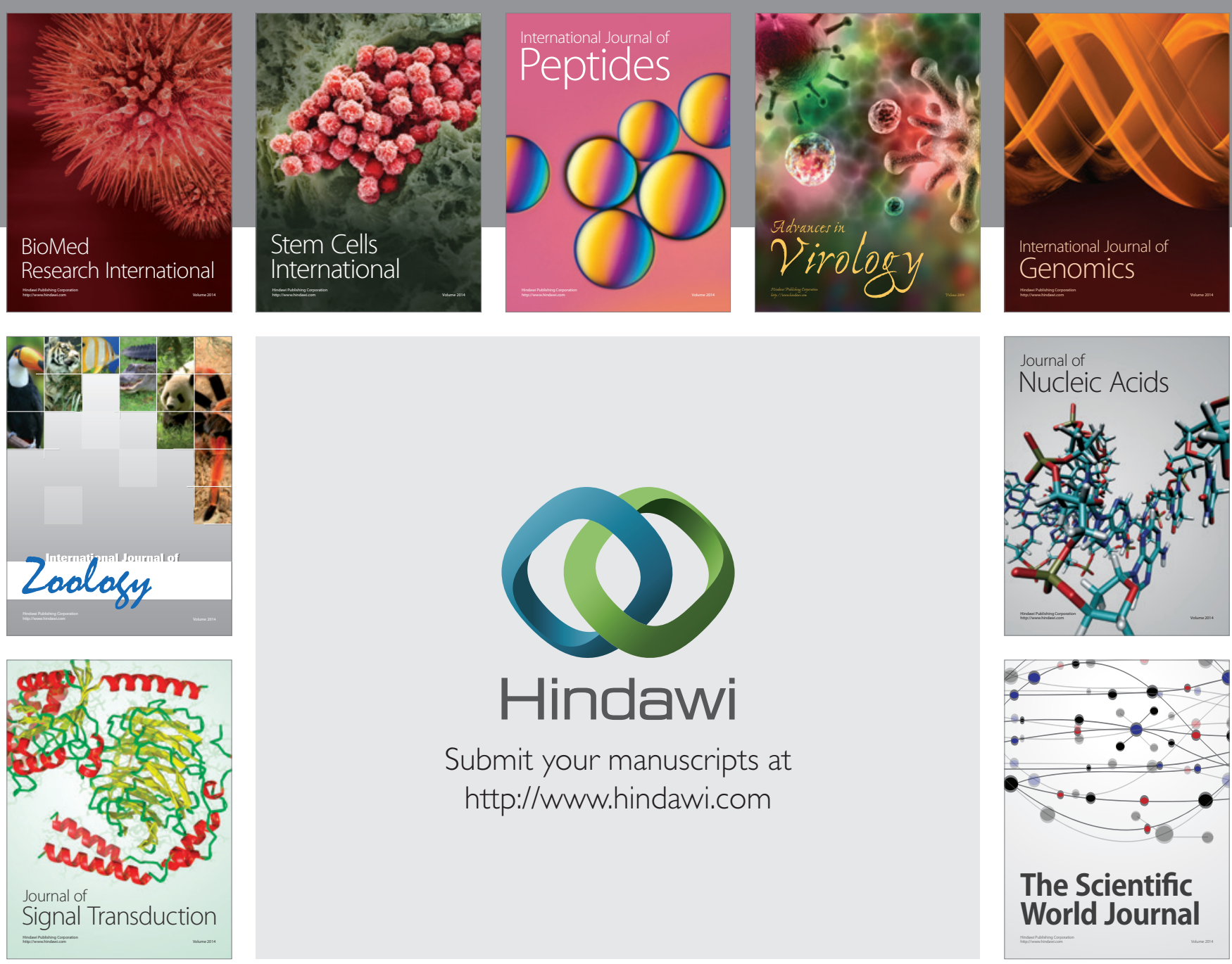

Submit your manuscripts at

http://www.hindawi.com
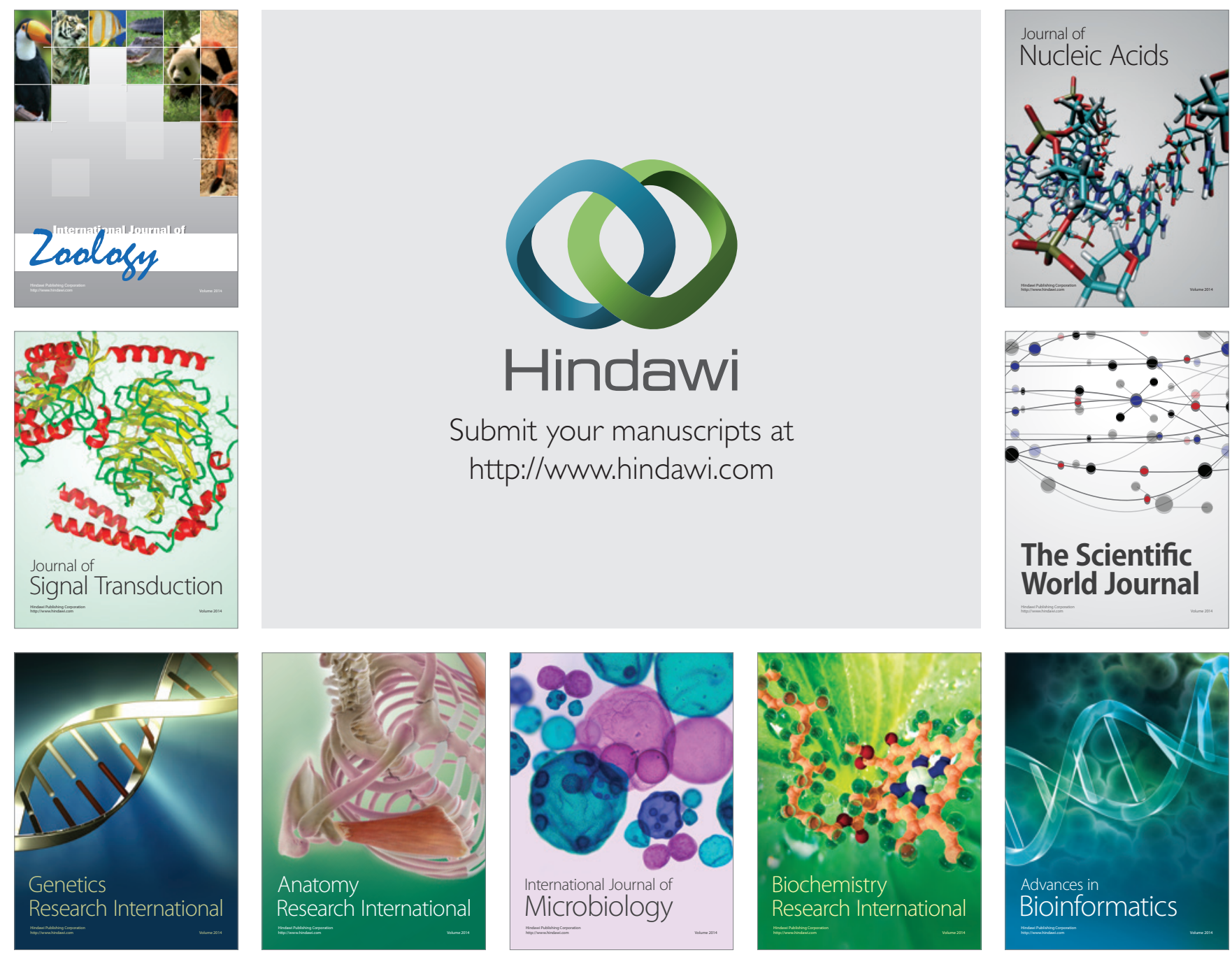

The Scientific World Journal
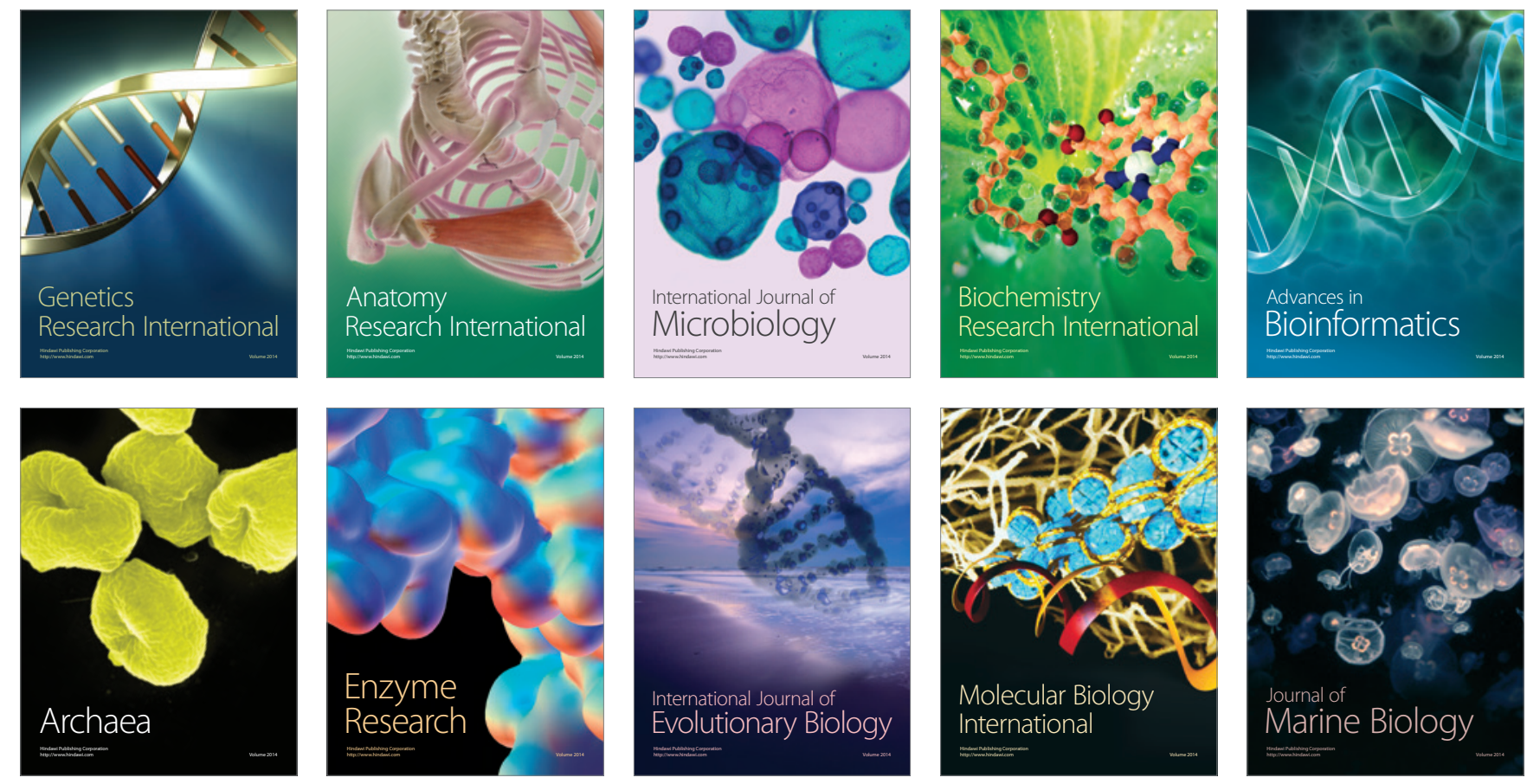